\title{
ANALYSIS OF NUCLEAR BASED ELECTRIC POWER GENERATION SYSTEM - AN LCA APPROACH
}

\author{
N. Leela Prasad ${ }^{1 *}$, P. Usha $\mathrm{Sri}^{2}$ and K. Vizayakumar ${ }^{3}$ \\ ${ }^{1}$ Vignan Institute of Technology and Science - Deshmukhi., T.S., India \\ ${ }^{2}$ UCE - Osmania University, Hyderabad., T.S., India \\ ${ }^{3}$ Bapatla Engineering College, Bapatla., A.P., India \\ ${ }^{1}$ Email: nlp123@ rediffmail.com*(Corresponding author) \\ 2Email: emailushasri@yahoo.com \\ ${ }^{3}$ Email: vizaya @gmail.com
}

\begin{abstract}
In a developing country like India with scarce hydrocarbon reserves and also due to variable nature of Renewables in terms of potential, penetration and technology, Coal must be relied upon as a source of energy in near future also, to meet the ever-growing demand for an instant form of energy i.e. Electricity. An alternative to not so clean source Coal appears to be Nuclear Power and this option can supplement and supplant our energy needs despite several concerns from various sources post-Fukushima Nuclear accident. This paper carries out a detailed LCA study of Nuclear based Electric Power Generation System with a wider scope that encompasses the waste disposal and spent fuel reprocessing phases, is modelled and run on SimaPro 9.0.0.48 LCA software with ECOINVENT 3.0 as database. This study also covers the all-important Inventory Analysis for the inputs used, raw material extracted and residuals consequently released to the environment. The results are expressed in terms of pre-defined energy metrics such as ERR and EPBT. Further, the study covers the environmental impact assessment category such as GWP and finally the results are presented with a $\mathrm{kWh}$ of electricity produced by this option as a functional unit. These investigations help energy planners and policymakers to compare various power generating options and justify the alternatives to meet future demand for electricity in a cleaner and more sustainable manner by keeping the spirit of Paris Climate Agreement in mind.
\end{abstract}

Keywords: Life Cycle Assessment (LCA), Energy Return Ratio (ERR), Energy Pay Back Time (EPBT), Global Warming Potential (GWP).

https://doi.org/10.47412/FWET1261

\section{Introduction}

Nuclear based Electric power generation system is a steam plant powered by thermal energy produced during a controlled nuclear fission process of nuclear fuel within a reactor instead of combustion of some conventional carbon-based fuels such as Coal. So, power derived here is broadly termed as Nuclear power and it can be considered as an alternative source of energy. But it does not fall under in the category of renewable sources of energy. Nuclear energy is a mature technology developed almost a century back unlike most of the renewables and its large-scale implementation is quite possible and well defined. It has a very high low-carbon advantage over fossil fuel-based energy systems. Due to larger initial investment on the 
system and risk premium involved in the fuel costs, Nuclear power is usually 10 per cent more expensive to generate than coal. But the fuel costs are smaller on a long-term basis and more predictable in comparison. On the other side of the coin, the huge risks involved in harnessing the Nuclear Power is evident from Chernobyl, Long-Island and Fukushima Nuclear disasters, which have put a large question mark on its future as a source of clean energy. With all the above proclaimed advantages and the inherent dangers involved with the system, an attempt was made to carry out a holistic study of it by LCA methodology.

\section{Systems to Harness Nuclear Power}

By absorbing a neutron, a nucleus of an atom splits into lighter nuclei and releases enormous amounts of energy which is usually termed as Nuclear Energy. It is in turn harnessed as heat in a setup called Nuclear Reactor. The chemical element used to produce nuclear power is Uranium and its energy content is so high that a gram of Uranium is equal to at least 3 tonnes of high-grade coal. The three isotopes most important for nuclear power are U-233, PU-239 and U-235. Out of these three, only U-235 is found in Natural Uranium mined from the earth at $0.7 \%$. The other two isotopes are derived from more abundant part of Natural Uranium i.e. U-238 by advanced nuclear processing techniques. As the reactor is presumed to be the heart of Nuclear based electric power generation system, all the reactors that are in use across the world are classified into two broad groups [1].

\subsection{Pressurized Water Reactors}

Pressurized Water Reactor (PWR) is a type of Nuclear Reactor which uses ordinary water as neutron moderator and coolant as well. The water in use as moderator and primary coolant is separate from the water in use to generate steam and drive a turbine. To harness the heat efficiently from the energy liberated during a Nuclear Reaction, the water that moderate the neutrons and cools the fuel elements is kept at pressures many times higher than atmospheric pressure so that it gets heated up without boiling.

A take-off from PWR is a Pressurized Heavy Water Reactor (PHWR) which uses deuterium isotope of Hydrogen called Heavy Water as the moderator and primary coolant. Heavy Water as moderator gives enhanced neutron economy and permits the use of natural uranium as fuel. Heavy water is commercially produced either by Girdler-Sulfide process or by Ammonia-Hydrogen process and it represents 10\% operational cost of PHWRs.

\subsection{Boiling Water Reactors}

Just like PWR, Boiling Water Reactor (BWR) uses ordinary water which is usually referred to as light water as both coolant and moderator. But unlike in PWR, there is no separate or secondary steam cycle. The water from the reactor itself gets converted to steam and is used directly to drive the turbo-generator. Popularity wise, BWRs are the second most commonly used reactors after PWRs.

\section{LCA Methodology}

It is essential to know which generating system gives the best return on energy invested in them. So, the performance of Nuclear Power generation system can also be analysed by the total energy inputs required to build and run a Nuclear Power plant and comparing them with the total energy it produces. One such analytical tool that can be used for this purpose is Life Cycle Assessment (LCA). The definition of LCA and its fundamental concepts, methodology and applications are described as part of the ISO 14040 - 14049 series of standards. As the energy consumption and emissions have a cause and effect sort of relationship, 
the Net Energy Analysis (NEA) of a system in conjunction with the evaluation of the system's environmental performance is commonly referred to as LCA. Some important applications of LCA are Environmental labelling of products, Identification of improvements in a method of Electricity Generation process and comparative assessment of various methods/options of Electricity Generation process.

The LCA methodology has four stages: Initiation / Goal Definition and Scoping, Inventory Analysis, Impact Assessment and Interpretation of Results to carry out Improvement Analysis [2].

\subsection{Initiation}

Initiation or Goal definition and scoping is the first step of any LCA study that defines the motive and technique for including energy performance and life cycle environmental impacts in the decision-making process. This study aims to carry out NEA and also to identify and quantify the environmental releases associated with $650 \mathrm{MW}$ Nuclear-based electric power generation system with a kWh electricity produced by it as the Functional Unit (FU). Finally, the study results will be presented in terms of pre-defined metrics for comparison with other electric power generating systems or options. This study also points out the hotspots where the process improvements are needed or new technologies are to be implemented. The system boundaries for this LCA are drawn as broadly as possible so that most of the processes necessary to produce electricity from nuclear fuel such as basic mining process, fuel preparation, plant construction, operation, spent nuclear fuel reprocessing, waste management and all the intermediate transport processes.

\subsection{Inventory Analysis}

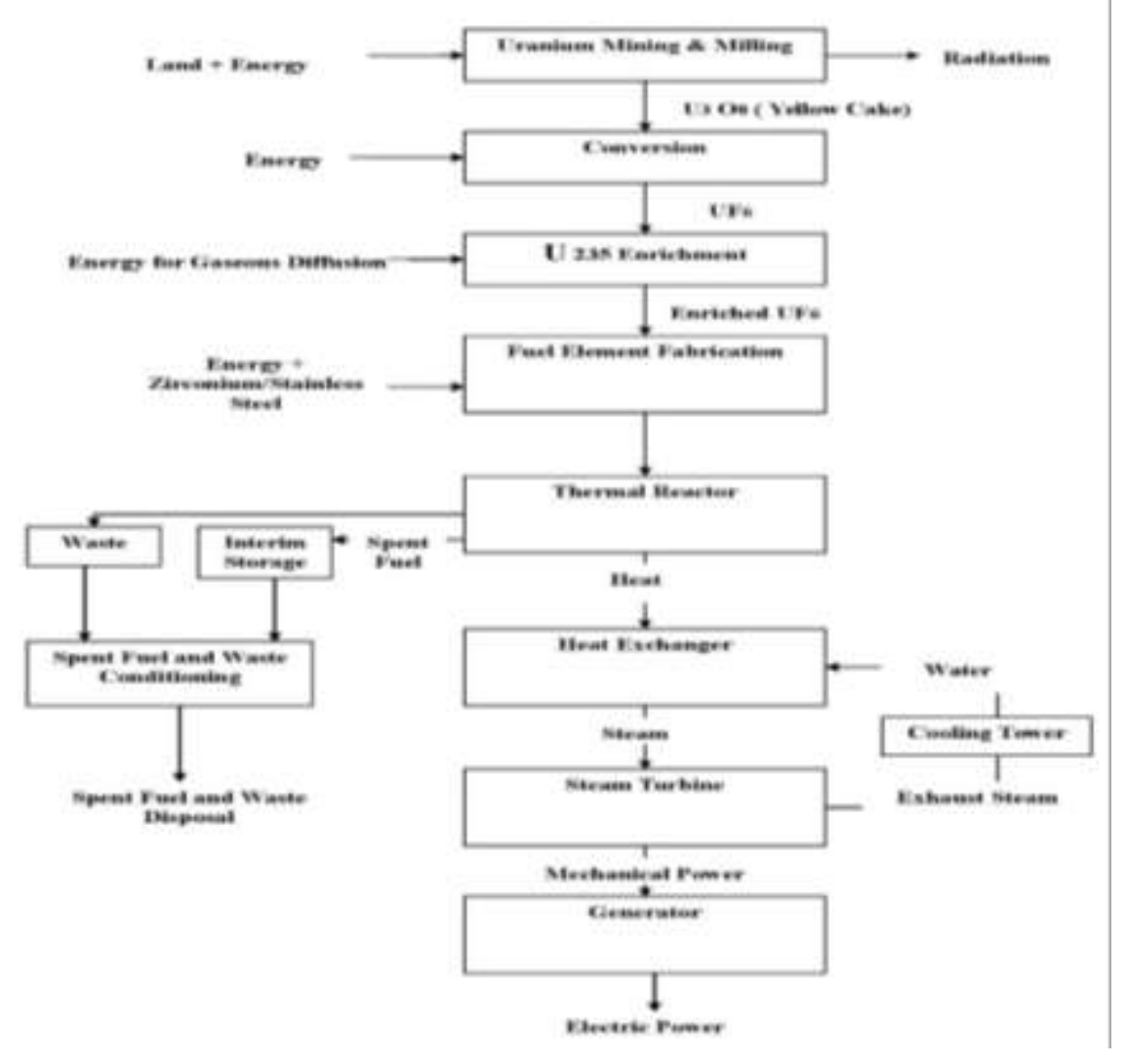

Figure 20: Process Flow Diagram depicting the System. 
Life Cycle Inventory Analysis (LCIA) is a phase during which the energy and raw material inputs, atmospheric emissions and other outputs are quantified for the entire life cycle of nuclear-based electric power generation system selected for this study. A most important step in the inventory analysis is the creation of a process flow diagram as shown in Fig.1 that will serve as the basis for the data collection. The process flow is divided into a series of interconnected unit processes. Their connections within the process chain are analysed. For each of these processes, all inputs and outputs are analysed. Finally, all those unit processes are summed up to give a comprehensive picture of the entire system [3].

\subsubsection{Uranium Mining \& Milling}

Uranium is extracted by any of these three processes: open-pit mining, underground mining and in situ leaching (ISL) based on ore body formation in earth's crust. With first two processes, the ore is transported to mill for separating the uranium from ore. In the process of in situ leaching, the removal of solid ore from the ground is not required and the uranium is leached from the ore by the use of acid or an alkaline solution. Uranium extracted through the mining is further processed in a mill so that it is leached from the ore either by using a solution. Finally, uranium is recovered from this solution using ion-exchange or solvent extraction process. The usable mill product is uranium oxide concentrate called yellowcake. To remove impurities and to increase $\mathrm{U}_{3} \mathrm{O}_{8}$ concentration in yellow cake, it is usually heated.

\subsubsection{Uranium Conversion \& Enrichment}

Natural uranium made up of two isotopes, $0.7 \%$ U-235 and $99.3 \%$ U-238. Out of these two isotopes, only U-235 is fissile material. The process of increasing the per cent of U-235 in large centrifuges is known as Uranium enrichment process. $\mathrm{U}_{3} \mathrm{O}_{8}$ or yellowcake must be converted into uranium hexafluoride $\left(\mathrm{UF}_{6}\right)$ gas, before passing it into a centrifuge for the enrichment process. The enrichment process is an energy-intensive process and it accounts for almost fifty per cent cost of nuclear fuel and also about $5 \%$ of the total cost of the electricity generated. It may become a major source of greenhouse gas emissions if the electricity used for enrichment is generated from the coal. Only PHWRs can make use of natural uranium as fuel by avoiding this energy-intensive enrichment process.

Other important unit processes of Nuclear Power Generation System are Build, Operation \& spent fuel reprocessing and Nuclear waste management at the downstream.

\subsection{Impact Assessment}

Impact Assessment is an evaluative process to assess the effects of emissions that are identified in the Inventory Analysis phase and their impacts on ecology, human health, natural resource depletion and socioeconomic aspects. The principal concern of the life cycle assessment methodology applied to energy systems is their likely contribution to climate change. Greenhouse gas emissions cause global warming and in turn contribute to climate change. So, Global Warming Potential (GWP) of a system is often calculated in terms of how much $\mathrm{CO}_{2}$ would be needed to produce a similar warming effect. This is called $\mathrm{CO}_{2}$ Equivalent. For example, 5 Tonnes of Methane would have a $\mathrm{CO}_{2}$ equivalent of $5 \times 25=125$ Tonnes and whereas $\mathrm{NO}_{\mathrm{X}}$ has 310 times more Global Warming Potential than $\mathrm{CO}_{2}$ itself [4].

\subsection{Improvement Analysis}

It is a common knowledge that the fossil-fuelled electric power generation system causes most emissions at the plant site, while the majority of greenhouse gas emissions with Nuclear based electric power generation system are caused in the upstream and downstream stages from the plant. In the upstream stages, uranium mining and enrichment are to be focussed for improvements as they are very energy-intensive processes, while in the downstream stages issues to be focussed for improvements are spent fuel reprocessing and radioactive waste management for its secure long-term storage. 


\section{Results based on Pre-defined Metrics}

A $650 \mathrm{MW}$ heavy water-moderated; pressurized water nuclear reactor based electric power generation system is modelled and run on SimaPro 9.0.0.48 software with ecoinvent 3.0 as a database, for carrying out this LCA study.

Energy Performance of the system is analysed based on a method called Cumulative Energy Demand (CED), which was published by ecoinvent as part of its 1.01 version and later expanded by PRé for energy resources available in the SimaPro database manual [5].

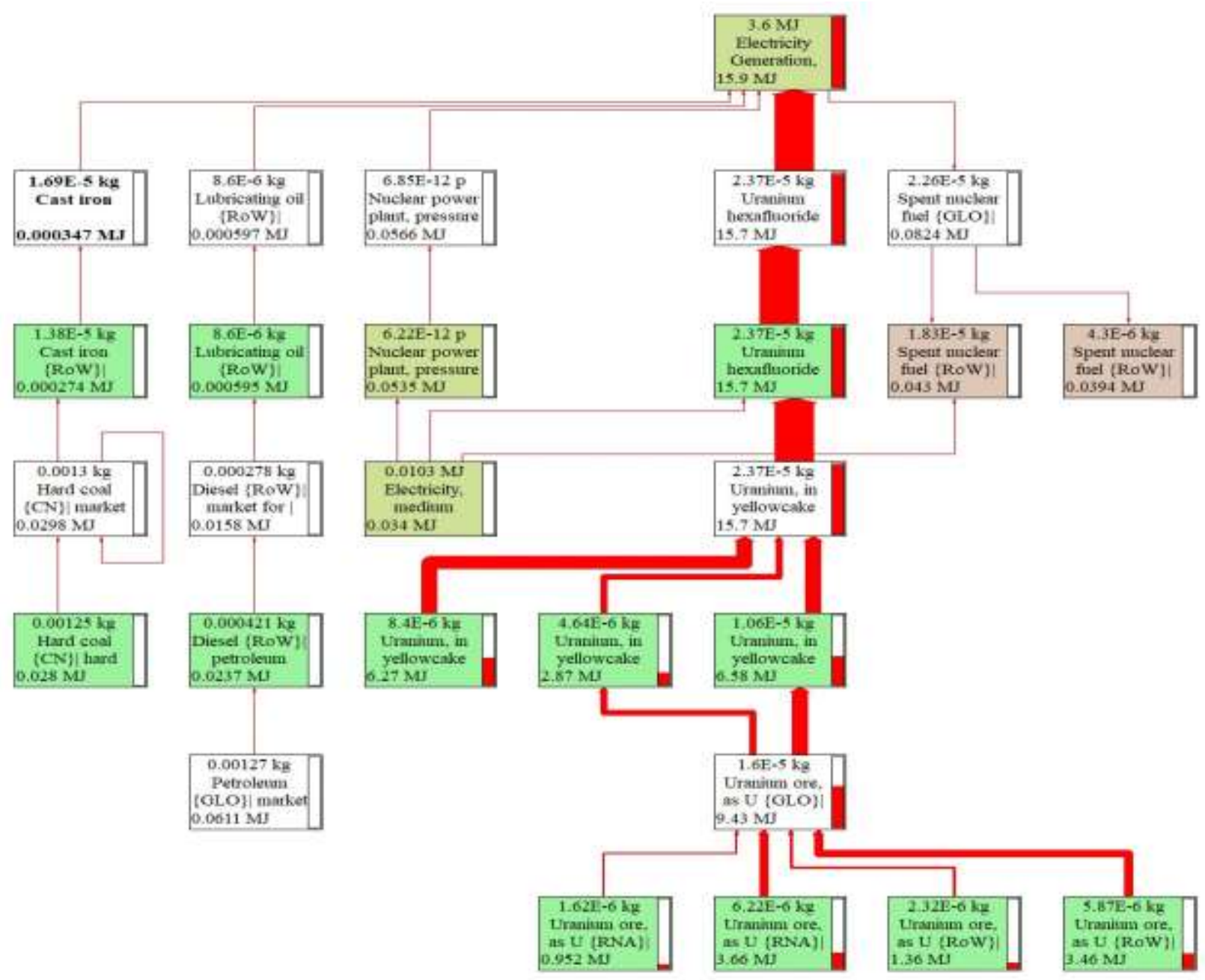

Figure 21: Model flow chart for a 650 MW Nuclear based Electric Power Generation System in SimaPro with cut-off value of $0.17 \%$ / CED Method.

The thick red connectors with arrowheads in Fig. 2, indicates the fact that the nuclear fuel cycle contributes majorly to the Cumulative Energy Demand (CED) of the system and the nuclear power plant itself contributes a little to CED over the entire lifetime. 
Figure 3 indicates the fact that the system under study depletes the Non-renewable, nuclear fuels to a large

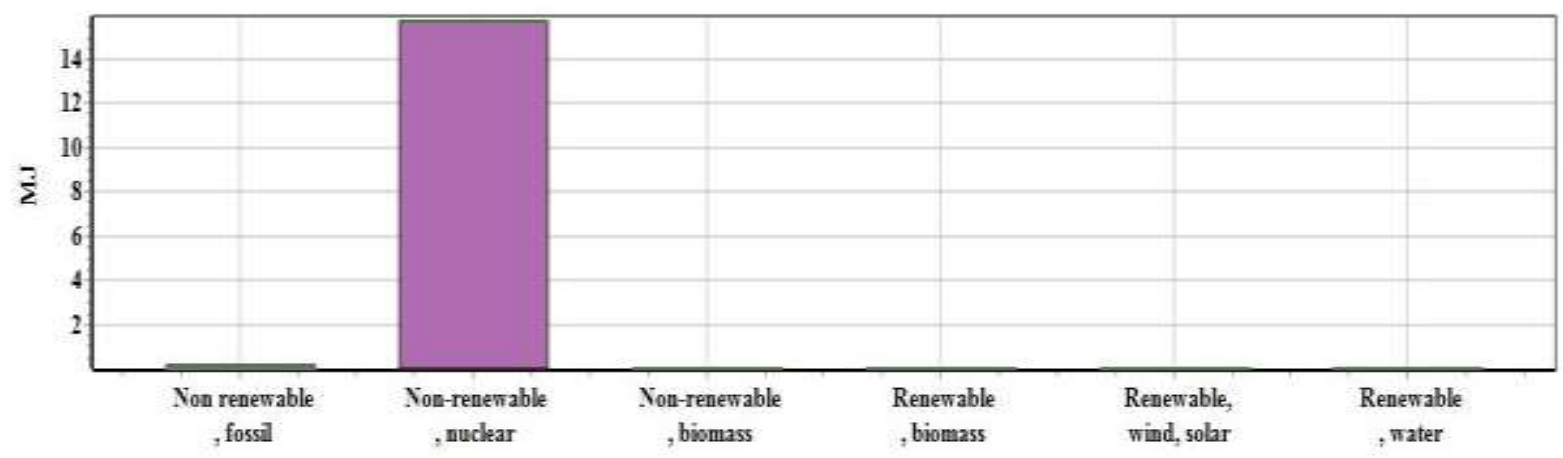

Figure 22: System Impact on various Energy Resources / CED Method.

extent and Non-renewable, fossil fuels to a very little extent.

\subsection{Energy Return Ratio}

Energy Return Ratio (ERR) is sometimes referred as Life Cycle Energy Efficiency (LCEE) [6] and it is a ratio of electricity output (FU) to the corresponding Cumulative Energy Demand (CED) by the system in primary energy terms, cumulated over its entire lifetime and here it is 30 years.

Energy Return Ratio (ERR) or Life-Cycle Energy Efficiency (LCEE)

$$
\begin{aligned}
& =\mathrm{FU} / \mathrm{CED} \\
& =1 \times 3600 / 15.9 \times 1000 \\
& =0.226(22.6 \%)
\end{aligned}
$$

To avoid any valuation issues, if $\mathrm{FU}$ is converted into primary energy terms based on $1 \mathrm{kWh}$ (primary energy equivalent $)=9.36 \mathrm{MJ}$ as per WEC, London., then

Energy Return Ratio (ERR) or Life-Cycle Energy Efficiency (LCEE)

$$
\begin{aligned}
& =\mathrm{FU} / \mathrm{CED} \\
& =9.36 / 15.9 \\
& =0.588(58.8 \%)
\end{aligned}
$$

\subsection{Energy Payback Time}

It is the time required to recover the Indirect Lifetime Energy Inputs in primary energy terms in all life cycle stages of the system including material embodied energies and A.C. power. This term 'EPBT' is generally used by energy policymakers for the renewable energy systems as they do not have any direct fuel energy inputs [7]. This metric does not apply to the system under study. Energy Return Ratio (ERR) or Life-Cycle Energy Efficiency (LCEE) is quite meaningful for this system as it takes the direct fuel energy inputs also into account. 
To analyse the System's environmental impacts, a method called IPCC 2013 is utilized in this study. It was developed by the International Panel on Climate Change as an update to an earlier method i.e. IPCC 2001. IPCC climate change factors are listed as part of this method with a timeframe of 20, 100 and 500 years [5]. Figure 4 is the network generated when a $650 \mathrm{MW}$ heavy water-moderated; pressurized water nuclear reactor based electric power generation system is modelled and run on SimaPro 9.0.0.48 software by using IPCC 2013 GWP (100a) method, with ecoinvent 3.0 as a database.

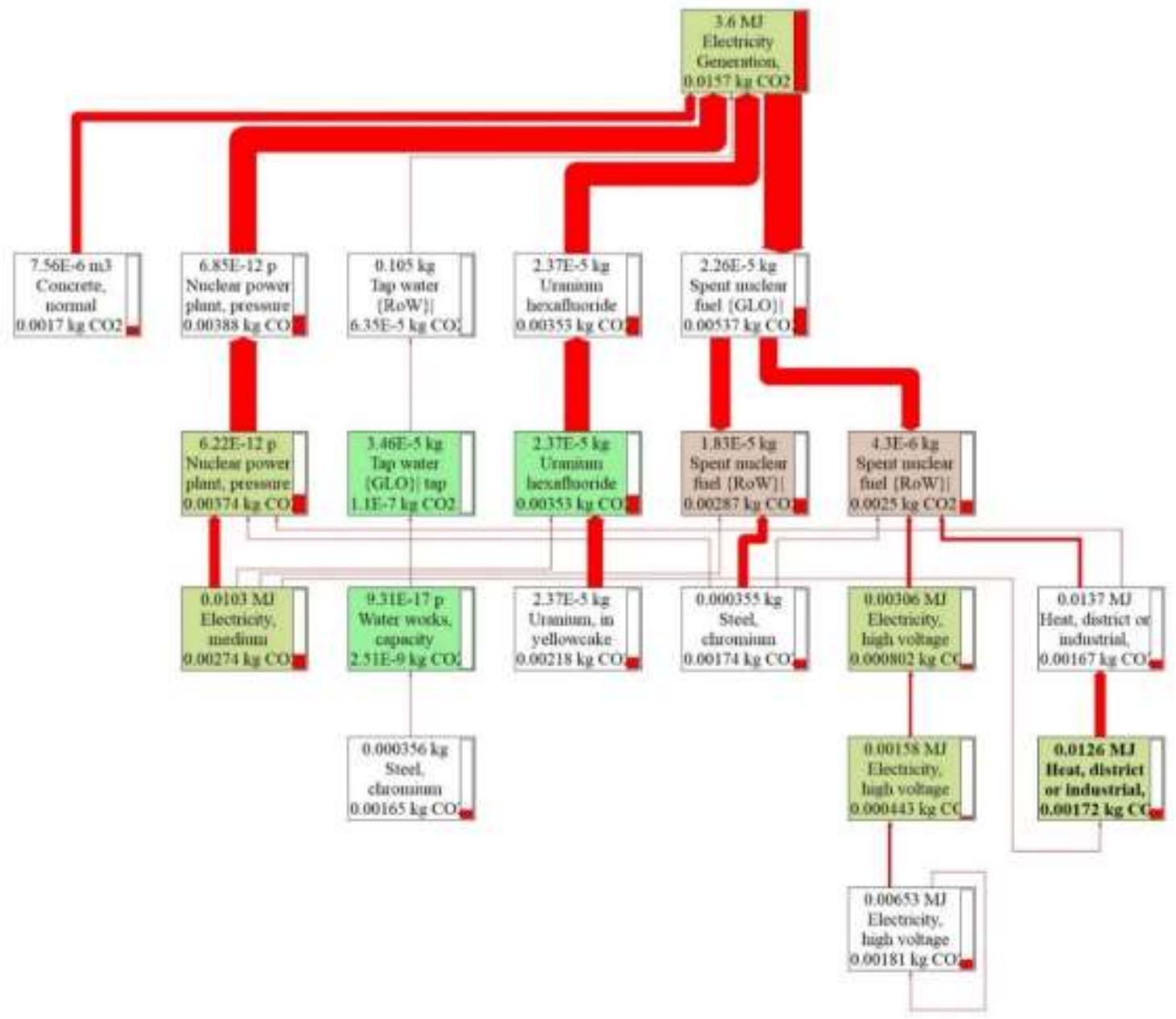

Figure 23: Model flow chart for a 650 MW Nuclear based Electric Power Generation System in SimaPro with cut-off value of $9.6 \%$ / IPCC 2013 GWP (100a) method.

\subsection{Global Warming Potential}

Based on the relative thickness of the red connectors in Fig. 4, all phases of the system's life cycle contribute more or less equally to the Global Warming Potential of the system and it is finally expressed in terms of $\mathrm{CO} 2$ - Equivalents per FU of the study. The direction of the Arrowhead of red connector representing Spent fuel reprocessing phase has a positive impact on the system, in reducing its GWP.

Global Warming Potential (GWP) of the System [6]

$$
\begin{aligned}
& =\text { Life-Cycle } \mathrm{CO}_{2}-\text { Equivalent Emissions } / \mathrm{FU} \\
& =0.0157 \mathrm{~kg} \mathrm{CO}_{2} \mathrm{e} / \mathrm{kWh}
\end{aligned}
$$




\section{Conclusions}

Despite the site-specific character of LCA results and the amount, source of energy inputs to the nuclear fuel cycle that has implications on Carbon Dioxide emissions of the system in any case, the Nuclear power has negligible emissions. The average emissions attributed to Nuclear based Electric power generation system from the number of studies are only $66 \mathrm{~g} \mathrm{CO} 2 \mathrm{e} / \mathrm{kWh}$ which is much lower than the value of 445 $1050 \mathrm{~g} \mathrm{CO} 2 \mathrm{e} / \mathrm{kWh}$ which were attributed in case of coal, oil, diesel and the natural gas-based electric power generating systems. This study attaches even less amount of Carbon Dioxide equivalent emissions, a mere $15.7 \mathrm{~g}$ per kWh of electricity generated by the system. Other results from the modelling done in this study have concluded that Energy Payback Ratio is not applicable for this system and is good and comparable with Wind Energy System as claimed in [8] and Energy Payback Time is also short if the fuel energy inputs are kept aside. Since its environmentally friendly credentials are comparable to Renewable energy Systems, India can opt for this system to meet the growing energy demand, with proper safety mechanism from radiation exposure and waste disposal techniques are in place.

\section{References}

[1] Timothy J. Skone, P.E., National Energy Technology Laboratory, Role of Alternative Energy Sources: Nuclear Technology Assessment, 2012.

[2] Comparison of Energy Systems using Life Cycle Assessment - A Special Report of the World Energy Council, July 2004.

[3] Technical Reports Series No. 425, "Country Nuclear Fuel Cycle Profiles (Second Edition), International Atomic Energy Agency", Vienna, 2005.

[4] Faisal I. Khan, Kelly Hawboldt, M.T. Iqbal. Life Cycle Analysis of Wind-Fuel Cell Integrated System. Renewable Energy 30, pp.157-177, 2005.

[5] Various authors, SimaPro Database Manual Methods Library, PRé, 2016.

[6] Paul J. Meier., Life Cycle Assessment of Electricity Generation Systems and Applications for Climate Change Policy Analysis., A dissertation submitted to University of Wisconsin - Madison, 2002.

[7] Leela Prasad N., Usha Sri P., Vizayakumar K. (2020) Life Cycle Assessment of a 100 kWp Solar PVBased Electric Power Generation System in India. In: Narasimham G., Babu A., Reddy S., Dhanasekaran R. (eds) Recent Trends in Mechanical Engineering. Lecture Notes in Mechanical Engineering. Springer, Singapore.

[8] Luc Gagnon, Camille Belanger, Yohji Uchiyama, "Life-cycle assessment of electricity generation options: The status of research in year 2001", Energy policy Volume 30, Issue 14, pp.1267-1278, 2002. 